\title{
Unlocking Supply Chain Disruption Risk within the Thai Beverage Industry
}

\begin{abstract}
Purpose: A growing need for global sourcing of business has subjected firms to higher levels of uncertainty and increased risk of supply disruption. Differences in industry and infrastructure make it more difficult for firms to manage supply disruption risks effectively. This study aims to extend developing research in this area by addressing gaps within existing literature related to environmental turbulence and uncertainties.

Design/Methodology/Approach: We test our model using data collected from 253 senior managers and directors in the Thai beverage industry using advanced statistical techniques to explore the relationship between representations of supply disruption risk and uncertainty.

Findings: The results show that both magnitude and probability of risk impact on the disruption risk, but the probability of loss is a dominant determinant. We also find that demand uncertainty and quality uncertainty affect the risk perception of purchasing managers, and are related to the magnitude of disruption risk, rather than the frequency of occurrence. Interestingly, our results show that quality uncertainty negatively impacts on the severity of disruption risk.
\end{abstract}

Research limitations/ implication: The construct validity of demand uncertainty was under the required threshold, intimating the need for further construct development.

Practical Implications: The framework provides managers with direction on how to formulate and target their disruption risk management strategies. The work also allows practitioners to critically reflect on implicit risk management strategies they may already employ and their effectiveness.

Originality/Value: The paper identifies key antecedents of supply disruption risk and tests them within a novel industrial context of the beverage industry and a novel national context of Thailand.

Keywords: Disruption risk, Logistics risk, Structural equation modelling (SEM), Beverage Industry, Thailand.

\section{Introduction}

Over the past decade, supply disruption risk has emerged as a distinct topic of supply management research (Norrman and Jansson 2004, Tomlin 2006, Wu et al. 2007, Yang et al. 2009, Srinivasan et al. 2011, Silbermayr and Minner 2013, Gülpınar et al. 2014). Supply networks now span multiple geographic regions, increasing the exposure of local firms to environmental and operational risk. For example, the 2011 Floods in Thailand interrupted local and global distribution channels, creating shortages of critical components across a wide range of industries, including electronics and automobiles. The disruption not only impacted traditional manufacturing sectors, but also food and beverage industries. For example, the Thai floods significantly affected the downstream supply chain of the beverage industry for over four months. Bars and supermarkets reported a shortage of beer, with distributors struggling to identify routes through which they could have their product delivered. The interruption of the beverage supply chain not only affected the retail outlets, but also caused a 
knock on effect on the entertainment sector as well as tourism in some of the popular holiday destinations within Thailand (Armstrong 2011).

This and other similar environmental incidents raise important issues for practitioners, whereby a significant event in an upstream supply chain member can have repercussions for downstream customers, as well as the entire supply chain (Rice and Caniato 2003), so creating supply disruption risk. Supply disruption is viewed as a "unplanned and unanticipated event that disrupt the normal flow of goods and materials within a supply chain and, as a consequence, expose firms within the supply chain to operational and financial risks" (Craighead et al. 2007, p.132). Ellis et al. (2010) define supply disruption risk, from the perspective of purchasing managers, as "an individual's perception of the total potential loss associated with the disruption of supply of a particular purchased item from a particular supplier" (p.36).

In this research, we focus on the supply disruption risk of distributors in the beverage industry. The challenge faced by distributors is to develop sophisticated supply operations that can match both suppliers' and retailers' needs. Beverage manufacturers regularly introduce new products with SKU proliferation and adjust package sizes. In order to keep inventory cost down, retailers tend to have smaller shipments (such as pallet-sized and carton-sized orders), but with greater order frequency (Terry, 2008). In addition, supply chain members need to cooperate in their supply operations in order to ensure product safety and regulatory compliance. As a result, beverage supply chains become more vulnerable when disruption occurs due to these supply chain characteristics, highlighting it as an interesting context in which to undertake research.

Existing literature provides significant insight into the management techniques of supply disruption risk (Norrman and Jansson 2004, Yang et al. 2009, Tomlin and Wang 2011, Ellis, 
Henry, and Shockley 2010). However, the environmental uncertainty factors which impact on supply disruption risk have received only limited attention. Environmental uncertainty refers to the degree to which the external environment of a firm, including market demand, logistics operation, supplier operation, and natural disaster is characterised by an absence of patterns with changes that are unpredictable. As a result, managers are not provided with sufficient direction towards the nature of disruption risk or upon how to established an appropriate risk management strategy. Ellis et al. (2010) and Srinivasan et al. (2011) begin to address this research gap by linking environmental factors with risk. Srinivasan et al. (2011) focus on environmental uncertainty which refers to product obsolescence, predictability of demand, action by competitors and technology change. Their findings state the relationship between SC partnership quality and SC performance is weakened under high environmental uncertainty but strengthened in the presence of risk. However, the relationships between the environmental uncertainty and risk are not directly investigated in their study. In comparison, Ellis et al. (2010) focus on a behavioural model that examines the buyer's risk decision making process. Specifically, their study investigates how risk perceptions impact buyer decision making that may lead to changing a supplier. However, their investigation of environmental factors is limited to the perspective of supply market factors and product characteristics rather than from the perspective of the uncertainty factors inside the supply chain.

Supply chain uncertainty refers to unexpected changes to supply chain member operations and the interactions between members (Jüttner et al. 2003). This study aims to address the research gap by examining important perturbation uncertainty factors in supply chains that include environment factors. Moreover, we investigate how supply chain uncertainty factors 
influence the distinctive dimensions of supply disruption risk within a specific industrial and national context.

Our study contributes to the body of supply chain risk management literature in a number of ways. First, this study provides insights into how the distributors' perceptions of supply disruption risk are formed. Secondly, we examine the environmental factors that drive supply disruption risk and affect managers' perceptions of risk dimensions (i.e. risk magnitude and risk probability). Thirdly, we scrutinise how the risk dimensions if magnitude and probability influence the overall supply disruption risk. In addition to the high level of disruption risk present in the beverage industry, this context was selected as it is one of the most attractive businesses in Thailand for global investors to capitalize, and one which has demonstrated consistent growth (NZTE 2011). The study will also contribute by developing a more comprehensive understanding of how perturbation factors can impact disruption, and by gaining insight into the representation of supply disruption. This will provide managers in beverage companies a stronger footing on which to establish a risk management strategy focused on lessening the negative effects of supply interruption. Focusing upon the Thai beverage industry also provides an appropriate context for the exploration of complex supply issues within a rapidly developing country missing from the majority of operations management research (Behara et al., 2014).

The proposed model of supply disruption risk is then presented, outlining the impact based upon the perspective of informants. This addresses the question: How does supply chain uncertainty influence the disruption risk in downstream supply chain within the Thai beverage industry? Therefore, this perspective can inform different parties within the supply network with a more developed picture of supply disruption risk. The work will also provide a 
foundation on which to base further research on supply interruption within developing countries.

This paper is organized as follows. Section 2 comprises a comprehensive literature review of supply disruption risk. In section 3, the model and hypotheses which examine the relationships among constructs are developed. The research methodology is addressed in section 4. In section 5, the analysis process and testing of the hypotheses is described. The research findings and managerial implications are discussed in section 6 , while section 7 concludes the study.

\section{Literature Review}

The meaning of risk has evolved overtime; risk varies for different areas and different people, depending on their individual perceptions of the world. Risk is generally described as a situation which would lead to negative consequences, and has a certain level of probability to occur. Dowling (1986) stated from the perspective of the decision theorists: "risk is the situation where a decision maker has a priori knowledge of both the consequences of alternatives and their probabilities of occurrence". Alternatively, scientific perspectives of risk are provided by Mitchell (1995), who defined risk as “...the probability of loss and the significance of that loss to the organisation or individual', Sjöberg et al. (2004) view perceived risk as "the subjective assessment of the probability of a specified type of accident happening and how concerned we are with the consequences" (p.8). Yates and Stone (1992) state risk refers to the judgement of potential loss likelihood and loss significance. Both loss likelihood and loss significant are considered important factors in the judgement process. The above definitions reflect that risk constitutes two major dimensions, the magnitude of the negative effect and the respective probabilities of occurrence. 
In supply management, risk can occur in every tier and is inherent due to information asymmetries that are present when operating across business units and firm boundaries. Thus, supply risk, can be defined as the unpredictability or uncertainty of events that can interrupt the overall, or have negative consequences on the supply chain (Tang and Musa 2011).

In addition, supply risk is usually linked with the uncertainty that is inherent in all supply chains. Jüttner (2003) claimed that supply chain risk originated from the uncertainties in the external supply chain, the internal supply chain, and from network related uncertainty. In the review study of Rao and Goldsby (2009), they categorized supply chain risk into environmental, industry, organizational, problem-specific and decision maker risk. All these different types of risks were constituted by various uncertainty variables.

Supply disruption risk is one of the sub-categories of supply chain risk. Supply disruption risk is caused by unforeseen events that interfere with the normal flow of materials/ products and, as a consequence, expose firms within the supply chain to operational and financial risks (Craighead et al. 2007). Providing an alternate view, Ellis et al. (2010) view the product and market characteristics as key factors in influencing perceptions of probability and magnitude of loss, and in turn affect the overall views of supply disruption risk.

Numerous research investigates disruption risk management practices, and informs managers of how to address material interruption issues (Tomlin 2006, Yang et al. 2009). Both industrialists and academics strive to identify ways to manage the disruption risk and to minimize the negative impact of supply chain interruptions. Norrman and Jannson (2004) develop a risk management tool to identify, evaluate, manage and monitor the disruption risk inherent in suppliers and sub-tier suppliers. Craighead et al. (2007) investigate the link between supply chain design and disruption risk, the risk mitigation capability of recovery and risk warning. Kleindorfer and Saad (2005) develop a conceptual framework to scrutinize 
the cooperation of risk assessment and mitigation that is considered essential to disruption risk management, helping to reduce disruptions and increase supply chain robustness. The results imply that a well-designed, strategic risk management system could reduce the probability of risk as well as absorb the magnitude of negative consequences.

Braunscheidel and Surseh (2009) examined the cultural antecedents which affect the organizational practice, in order to improve supply chain agility and mitigate disruption risk across different cultural contexts. Thun and Hoenig (2011) empirically examined the preventative and reactive supply chain risk management practices that impact firm performance in the automobile industry. They emphasize that supply chain risk management practices should include both preventive and reactive approaches, since different approaches have their own particular strengths in dealing with various types of supply chain vulnerability. In summary, current literature identifies a wide selection factors impacting supply disruption risk, as well as direction on how they may be managed to improve supply function.

\section{Theoretical Development}

The development of our supply disruption risk model is based on the Yates and Stone (1992) risk perception framework. Yate and Stone's model presents a structural model of how different elements affects decision maker's risk perceptions, so as to affect the decision making. In the literature, there are other models representing risk perception. For example, Slovic et al.'s (1987) risk perception model which includes multiple dimensions of risk perception, and (McDaniels et al., 1995, Savadori et al., 2004, Feng et al. 2010). Slovic et al.'s (1987) risk perception approach is a useful tool to analyse and predict decision makers' responses to various risks by identifying their similarities and differences. Also, it has been widely adopted in risk and applied psychology literature in various areas, including automobile defect, product recall, and bio-technology. However, most of these risk perception 
models are representing the lay people's risk perception and its profiling. In Yate and Stones's model, it provides an interesting insight about how risk perception is constituted when decision makers face risky decision making. Also, it provides a more holistic view of the risk presentation and its elements which are seldom mentioned in SCM literature.

Yates and Stone's framework consists of four stages: (i) understanding the situation, (ii) representation of loss and the loss likelihood, (iii) representation of overall risk, and (iv) making a decision based in the essential stages of the process. Yates and Stone's framework describes the loss significance (risk magnitude), loss likelihood (risk probability), and overall risk as related elements, which all distinctively represent risk (Ellis et al. 2010). Yates and Stone (1992) claim that their framework is more suitable to describe the risk representation in social situations rather than a strictly personal setting. Thus, it is suitable to explain the "risk structure" of supply disruption risk.

Ellis et al. (2010), based on Yale and Stone's (1992) framework, developed a disruption risk decision model to investigate the buyer's decision in changing supplier after the buyer perceives risk from environmental factors. Their work focuses on examining the behavioural response of the buyers (i.e. searching an alternative). In contrast, we aim to investigate the representation of risk and how the supply disruption risk is influenced by supply chain uncertainty factors. Therefore, we conceptualize our model according to the first three stages of the Yates and Stone framework, as those stages provide a clear picture of the structure of risk. Moreover, the behavioural/response action of the company is not the focus in this study, so it is not appropriate to conceptualize a "response decision" construct into our model justifying the removal of the $4^{\text {th }}$ stage of Yale and Stone's framework.

In our proposed model, "understanding the situation" (referring to stage 1 in Yates and Stone's framework) is conceptualized as the supply chain environment that affects 
representations of supply disruption risk. We focus on the uncertainties inside the supply chain environment, including a range of risk sources in perturbation issues (i.e. transportation delays, port stoppages, accidental and natural disasters, quality issues, demand issues) (Wu et al. 2007, Germain et al. 2008, Lockamy III 2014). Thus, some external environmental factors, such as competitors' actions, technological changes, consumer tastes and preferences are not included (Srinivasan et al. 2011). This focus emphasises general characteristics of the supply environment that are more likely to impact supply performance that are not defined by specific product-market characteristics. This perspective provides a foundation for the research that increases the relevance to non-beverage supply environments. To explore uncertainty within the beverage supply context, we draw from Waters's (2007, p.17) definition of uncertainty and adapt it into a definition of supply chain uncertainty:

Supply chain uncertainty describes the situation where managers can list perturbation events that might happen in the supply chain in the future, but have no idea about which will actually happen or their relative likelihoods in supply chain operations.

In order to structure uncertainty within the research, we conceptualize supply uncertainties as three uncontrollable factors in supply environments: logistics uncertainty, quality uncertainty and demand uncertainty. We acknowledge that these perturbation attributes do not represent a comprehensive list of all supply chain environmental factors affecting supply disruption risk. Instead, our purpose is to illustrate how these uncertainty factors, that affect most supply chains, are of relevance to the complex nature of the beverage supply chain and facilitate representation of the supply disruption risk. 
To account for the impact of the context in which the research is conducted, every related term and concept proposed in this study has been considered in terms of its relevance to Thailand.

Figure 1 shows our conceptual model of supply disruption risk. To address limitations of our definition and conceptual model, the following section will assess potential antecedents of supply disruption risk, and begin to formulate research hypotheses.

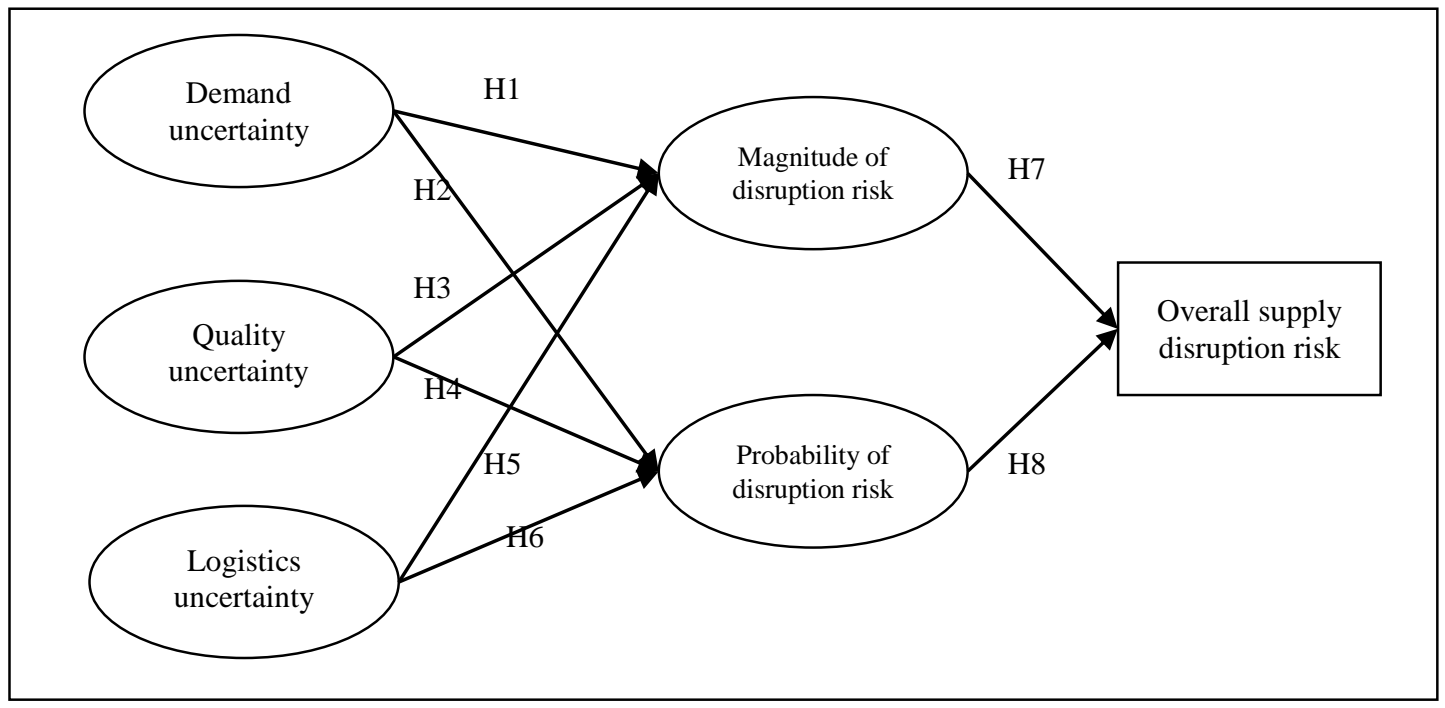

Figure 1. Conceptual model of supply disruption risk

The Antecedents of Supply Disruption Risk

\section{Demand Uncertainty}

Demand uncertainty is associated with the predictability of product demand (Lee 2002), and has been found to have a direct impact on the supply chain process variability (Germain et al. 2008). Hendricks and Singhal (2005) state that supply disruption risk is an indication of firms' inability to match demand and supply. Srinivasan et al. (2011) state demand uncertainty is viewed as another risk which can cause supply chain disruption. The demand uncertainty stems from mismatching between a company forecast and actual demand and poor coordination to suppliers. 
In the context of the beverage industry, the distributors need to accommodate smaller quantity orders from retailers (such as half pallet-sized order), SKU proliferation, and mixpackaging (Terry 2008). Such characteristics of the beverage industry create considerable challenges for downstream parties by increasing demand uncertainty. In addition, news and rumours related to price increases can impact customer demand, and consequently have a considerable impact on the ability to meet inventory requirements across the supply chain, so increasing supply disruption risk (Chen et al. 2000).

The 'grey' market is another factor that can disrupt the supply chain activities (Tyler et al. 2006). Illegally imported beverage products can offer an attractive price to the buyer and introduce additional variation to downstream customer demand received through official distributors. These, 'grey' imports can increase the demand uncertainty in the market place through introducing further variation (Chen et al. 2000).

In short, these demand uncertainty factors can negatively affect the accuracy of demand forecasting so increasing supply disruption risk. Thus, in order to examine the relationship of the demand uncertainty to both the magnitude and probability of supply disruption risk, the following hypotheses are proposed:

H1. The level of demand uncertainty is positively associated with the magnitude of supply chain disruption.

$\mathrm{H} 2$. The level of demand uncertainty is positively associated with the probability of supply chain disruption.

\section{Quality Uncertainty}

The uncertainty of product quality is another area of concern for many organizations. It is often necessary for companies to undertake inspection of incoming goods in order to establish the standard of received products. Quality uncertainty can cause a cascading effect through a 
supply network, until issues reach the final consumer (Giunipero and Eltantawy 2004). Revilla and Sáenz (2014) state quality failure of finished goods are one of the major risk sources that result in discontinuities in the supply chain. If received products are unacceptable, supply disruption risk is increased as a result of the need to wait for replacements of an acceptable quality. Tse and Tan (2012) claim that low levels of product quality can result in product recalls, which can lead to the disruption of normal goods flow and increase costs through reverse supply chain activities. With the low switching costs to customers, the impact of quality uncertainty is more significant for the beverage industry, since the impact of a quality related issues may have long-term implications on customer perceptions and company reputation.

Warehousing operations within the beverage industry present a significant cost (Gebennini et al. 2013) and source of quality risk. Failure in temperature control of chilled drinks, combined with the wide range of mix and pack operations required by end-users increase the risk of product quality and breakage problems. Furthermore, problems of breakages and quality issues cause extra work for warehouse staff, such as the segregation of suspect cases and pallets, removing damaged items, waiting for placements and repackaging cases and pallets with intact bottles (Terry 2008), all of which induce rework causing extra delays for shipments. Moreover, product quality problems also lead to further supply chain disruptions through leftover stock affecting the flow of products across different supply chain tiers.

From the above arguments, the following hypotheses are proposed:

H3. The level of quality uncertainty is positively associated with the magnitude of supply chain disruption.

H4. The level of quality uncertainty is positively associated with the probability of supply chain disruption. 


\section{Logistics Uncertainty}

Logistics uncertainty is viewed as an uncertainty factor that causes a delay or an interruption originating from logistics partners or natural disasters during the transportation process to customer. Chopra and Sodhi (2004) state that logistics disruption is considered a subset of the drivers of disruption risk. Wilson (2007) claims that an interruption caused by transportation only stops the flow of goods, so it is less severe than other types of risk drivers, such as supplier plant shutdowns. An interruption in transportation can be caused by labour disputes, terrorist activities, natural disasters and infrastructure failures transportation. (Chopra and Sodhi 2004, Wilson 2007, Lockamy III 2014). Moreover, an interruption caused by transportation carrier failures and blocked roads are another source of supply chain disruption (Revilla and Sáenz 2014). This type of transportation interruption will only temporarily stop particular parts of the supply chain network, and not interrupt the whole supply chain (Wilson 2007). In the context of Thai beverage industry, transportation carrier failure and blocked roads are mainly caused by flooding (Haraguchin and Lall 2014). Thus, logistics uncertainty influences supply disruption risk via the delays it introduces into the delivery schedule, the inability to control logistics partners, the inability to control third party logistics providers and interruption caused by natural disasters.

From the above arguments, the following hypotheses are proposed:

H5. The level of logistics uncertainty is positively associated with the magnitude of supply chain disruption.

H6. The level of logistics uncertainty is positively associated with the probability of supply chain disruption.

The Perspective of the Supply Disruption Risk 
It is claimed that the overall supply disruption risk is represented by probability and magnitude of supply disruption. The risk model presentation reflects the fact that risk includes both the severity of possible outcomes and the distribution of respective probabilities for each outcome (Norrman and Jansson 2004, Dowling 1986). The probability of supply disruption risk is defined as the perceived likelihood that the normal flows of goods in downstream levels will be interrupted; the magnitude of supply disruption risk is given by the severity of the impact experienced by the supply network as a result of the incident. Thus, the overall supply disruption risk is defined as the obstacles that are formed by different patterns of any activities which affect the flow of goods in downstream levels of the supply chain (Cunningham 1967, Peter and Ryan 1976). Therefore, we propose the following hypotheses:

H7. The level of magnitude of supply disruption risk positively affects the level of overall supply disruption risk.

H8. The level of probability of supply disruption risk positively affects the level of overall supply disruption risk.

\section{Research Methodology}

In this research, a quantitative approach is chosen as the research methodology for investigating the representation of supply chain disruption risk. By the research acknowledging the impact of the subjective risk perceptions of practitioners, an more objectivist, quantitative approach reflects the systematic nature of the analysis of supply chain risk, providing more generalizable result. The quantitative approach is thus considered a more appropriate method to provide a clear understanding of disruption risk in Thai beverage industry. The quantitative approach is more likely to account take account of variations in individual perceptions, and thus the developed environmental uncertainty measurement instruments can be applied reliably within subsequent studies. 
In order to adopt an appropriate measurement instrument, for some of the constructs (i.e. magnitude of risk, probability of risk, and overall risk) we have undertaken a thorough literature review to identify and modify scales used in past research to ensure appropriateness for the context under investigation. Some question items that are newly created are based upon the literature review and related theoretical foundations presented in the previous section (i.e. demand uncertainty, quality uncertainty, and logistics uncertainty). To account for and validate the relevance of the newly developed constructs, the questionnaire items were reviewed by three academics and three practitioners to ensure content validity. Some measurement items are developed specifically for the context of the Thai beverage industry. For example, grey market context (i.e.DU5), logistics uncertainty covers the aspects of low dependability (LU1), poor fleet management (LU3), and the flooding (LU4). Moreover, as the question items of the constructs demand uncertainty, quality uncertainty, and logistics uncertainty are newly created, we also adopt the scale development approach by Menor and Roth (2007) as the skeleton, and combine this with steps suggested in the literature (Churchill 1979, DeVellis 2003, Hinkin 1995, Kaynak and Hartley 2006, Netemeyer et al. 2003, Schwab 1980). We then form systematic procedures to develop and validate the measurement of supply chain uncertainty. The procedures of the scale development are presented in Appendix 2.

In addition, stage 3 in Appendix 2 was repeated during the scale development process, due to the result of the first-round of the content validity test of the scale items was not satisfactory. The expert panel provided valuable feedback regarding the constructs and useful comments on the content validity of the proposed items. The items were revised and the definitions of supply chain uncertainty factors were re-specified in accordance with the feedback from the expert panel. Particularly, the measurement items in the construct 'demand 
uncertainty' and 'logistics uncertainty' were revised extensively in order to fit the Thai beverage industry context. The revised scale items were presented in Appendix 1.

Since our target respondents were directors and managers in Thai firms, the questionnaire was translated into Thai. We consulted a leading scholar in Thailand to ensure the measurement items in Thai reflected the business environment faced by the Thai beverage industry. According to the steps proposed by Brislin (1980), the Thai questionnaire was subsequently translated back into English by a third party translator to make sure that the measurement items accurately reflect the original meanings.

To ensure rigor of the research process, two statistics software programmes were applied. SPSS v22 was used as a tool to conduct the reliability test of the different constructs through exploratory factor analysis (EFA). Lisrel 8.54 was then used as the major software package in conducting Confirmatory Factor Analysis (CFA) and Structural Equation Modelling (SEM).

SEM was the core methodology used for analysing the primary data obtained from the questionnaire survey and allowed the eight hypotheses to be tested simultaneously, to determine the consistency between the model and the data. Also, it is a superior multivariate technique that can improve statistical estimation by not overlooking measurement error.

In the analysis, CFA was initially conducted to test the measurement model associated with supply disruption risk. Then, SEM was employed to test the hypothesized relationships within the structural model (Figure 1).

Data Collection

\begin{tabular}{|l|l|l|l|}
\hline The position of respondent & $\%$ & The position in supply chain & $\%$ \\
\hline CEO/GM/Director & $86 \%$ & Wholesaler & $42 \%$ \\
\hline Supply chain manager & $4 \%$ & Agent & $15 \%$ \\
\hline Regional sales/ Area manager & $4 \%$ & Distributor & $43 \%$ \\
\hline Purchasing manager & $4 \%$ & & \\
\hline Others & $2 \%$ & & \\
\hline Annual revenue of the firm & & Firm size & \\
\hline
\end{tabular}




\begin{tabular}{|l|l|l|l|}
\hline$>\mathrm{B} 10,000,000$ & $62 \%$ & $<250$ & $70 \%$ \\
\hline $\mathrm{B} 5,000,000-\mathrm{B} 10,000,000$ & $30 \%$ & $>250$ & $30 \%$ \\
\hline$<\mathrm{B} 5,000,000$ & $8 \%$ & & \\
\hline
\end{tabular}

Table 1. Profile of survey respondents

For our data collection process, we adopted Dillman's (1978) survey methodology. A Thai business research and consultancy firm (TCS) was employed to assist the administration of the formulated survey instrument. Target informants were the senior managers/directors responsible for supply chain operations in distributors, agents and wholesalers in all regions of Thailand. Initial mailings were sent, followed by reminders after two weeks, with followup phone calls if necessary. Of the 1500 entries on the mail-list provided by TCS, 1250 had valid addresses. After sending out 1250 surveys, 270 responses were received. This represented a $21.6 \%$ response rate, which was considered acceptable and consistent with other survey based research. A total of 253 usable responses were analysed, after removing inappropriate titles and deleting surveys with missing data. The demographic information of the respondents is summarized in Table 1. Respondents were asked to answer each question using a 7-point Likert-scale ("Strongly Disagree" - 1 to "Strongly Agree" - 7) based on the degree of agreement with the listed statement.

\section{Analysis and Findings}

\section{Assessment of Unidimensionality}

The unidimensionality of the constructs is addressed by using EFA. All the measurement items are aggregated to run EFA. The varimax method is adopted, since it is one of the most widely used EFA rotation methods. First, the Kaiser-Meyer-Olkin test (KMO) and Bartlett's Test of Sphericity are run to test the sampling adequacy. The result shows that KMO is computed to be 0.762 and the Bartlett's test is significant $(\mathrm{p}=.000)$. Both tests indicate the 
sample adequacy for running EFA. The Eigenvalues for the four constructs were greater than 1.0. The lowest percentage of variance of the items extracted in communality is 0.556 , higher than the threshold, 0.50. DU1 and DU3 were dropped as they were not grouped in the assigned construct. Overall, all the items were not highly cross-loaded with other factors. Therefore, the unidimensionality of each dimension is supported.

\section{Measurement Model}

The CFA was conducted to test the measurement model for overall fitness, in line with an acceptable degree of fitness suggested by Shah and Goldstein (2006) (see Table 2). The item loading and composite reliability of each construct are listed in Table 3 and the Average Variance Extracted (AVE) values and $\phi^{2}$ values are shown in Table 2. As shown in Table 3, all factor loadings $(\lambda)$ are greater than 0.50 . Most of the composite reliabilities are greater than 0.70 except demand uncertainty (0.68). As it is just slightly lower than the threshold, so we decide to keep this demand uncertainty construct. Based on these results, we are confident that the five constructs show acceptable convergent validity. Moreover, for assessing the discriminant validity of these five constructs, all the AVE values for each pair of constructs are higher than the square of the inter-correlation between any two constructs $\left(\phi^{2}\right)$ in the model (see Table 3). This provides good evidence of discriminant validity (Fornell and Larcker 1981). However, the Cronbach's alpha of demand uncertainty is 0.675 , which is 0.025 lower than the accepted lower limit (Nunnally 1978). Since it is only slightly lower than the acceptable boundary, and demand uncertainty is one of the major uncertainty factors that practitioners face, we decided to tentatively keep the demand uncertainty in the measurement and structural models. For all remaining constructs the Cronbach's alpha was acceptable, with all values greater than 0.76 .

\begin{tabular}{|l|l|l|l|l|l|l|l|l|}
\hline Model & $\chi^{2}(\mathrm{df})$ & $\begin{array}{l}\text { RMSEA } \\
{[90 \%}\end{array}$ & CFI & NNFI & NFI & $\begin{array}{l}\text { Normed } \chi^{2} \\
\left(\chi^{2} / \mathrm{df}\right)\end{array}$ & SRMR & AGFI \\
\hline
\end{tabular}




\begin{tabular}{|l|l|l|l|l|l|l|l|l|}
\hline & & $\begin{array}{l}\text { confidence } \\
\text { interval] }\end{array}$ & & & & & & \\
\hline $\begin{array}{l}\text { Measurement } \\
\text { model }\end{array}$ & $272.75(109)$ & $\begin{array}{l}0.077 \\
{[0.0658,} \\
0.0887]\end{array}$ & 0.92 & 0.90 & 0.88 & 2.502 & 0.065 & 0.841 \\
\hline Structural model & 350 & 0.079 & 0.92 & 0.89 & 0.87 & 2.80 & 0.070 & 0.829 \\
& $(125)$ & $\begin{array}{l}0.0688, \\
0.0900]\end{array}$ & & & & & & \\
\hline
\end{tabular}

Table 2. Model fit

\begin{tabular}{|l|l|l|l|l|l|}
\hline & 1 & 2 & 3 & 4 & 5 \\
\hline 1. Quality Uncertainty & $\mathbf{0 . 5 1 8}$ & & & & \\
\hline 2. Demand Uncertainty & 0.023 & $\mathbf{0 . 4 1 9}$ & & & \\
\hline 3. Logistics Uncertainty & 0.073 & 0.260 & $\mathbf{0 . 5 0}$ & & \\
\hline 4. Risk Magnitude & 0.020 & 0.168 & 0.044 & $\mathbf{0 . 5 7 1}$ & \\
\hline 5. Risk Probability & 0.007 & 0.055 & 0.396 & 0.063 & $\mathbf{0 . 5 4 7}$ \\
\hline
\end{tabular}

Table 3. Assessment of discriminant validity

Note: Bold numbers on the diagonal show the AVE of the construct; Number below the diagonal represent square of construct correlations $\left(\phi^{2}\right)$

\begin{tabular}{|l|l|l|l|l|}
\hline N=253 & Mean & $\begin{array}{l}\text { Item Loading } \\
(\lambda)\end{array}$ & $\begin{array}{l}\text { Composite } \\
\text { reliability }\end{array}$ & $\begin{array}{l}\text { Cronbach's } \\
\text { alpha }\end{array}$ \\
\hline Quality Uncertainty & & & 0.81 & 0.809 \\
\hline QU1 & 2.75 & 0.73 & & \\
\hline QU2 & 3.28 & 0.72 & & \\
\hline QU3 & 3.04 & 0.75 & & \\
\hline QU4 & 3.21 & 0.67 & & \\
\hline Demand Uncertainty & & & 0.68 & 0.675 \\
\hline DU2 & 5.43 & 0.57 & & \\
\hline DU4 & 5.44 & 0.69 & & \\
\hline DU5 & 5.25 & 0.68 & & \\
\hline Logistics Uncertainty & & & 0.80 & \\
\hline LU1 & 5.27 & 0.62 & & \\
\hline LU2 & 4.79 & 0.76 & & \\
\hline LU3 & 4.11 & 0.76 & & \\
\hline LU4 & 4.85 & 0.68 & & \\
\hline Risk Magnitude & & & 0.798 & \\
\hline MD1 & 5.62 & 0.74 & & \\
\hline MD2 & 5.74 & 0.84 & & \\
\hline MD3 & 5.64 & 0.67 & & \\
\hline Risk Probability & & & & \\
\hline RP1 & 4.92 & 0.69 & & \\
\hline
\end{tabular}




\begin{tabular}{|l|l|l|l|l|}
\hline RP2 & 4.51 & 0.89 & & \\
\hline RP3 & 4.77 & 0.63 & & \\
\hline
\end{tabular}

Table 4. Results of the confirmatory factor analysis (measurement model)

\section{Structural Model}

For the second step of the analysis, the SEM approach was employed to test the hypothesized relationship in the structural model. The model fit is included in Table 4, and Figure 2 summarizes the model result.

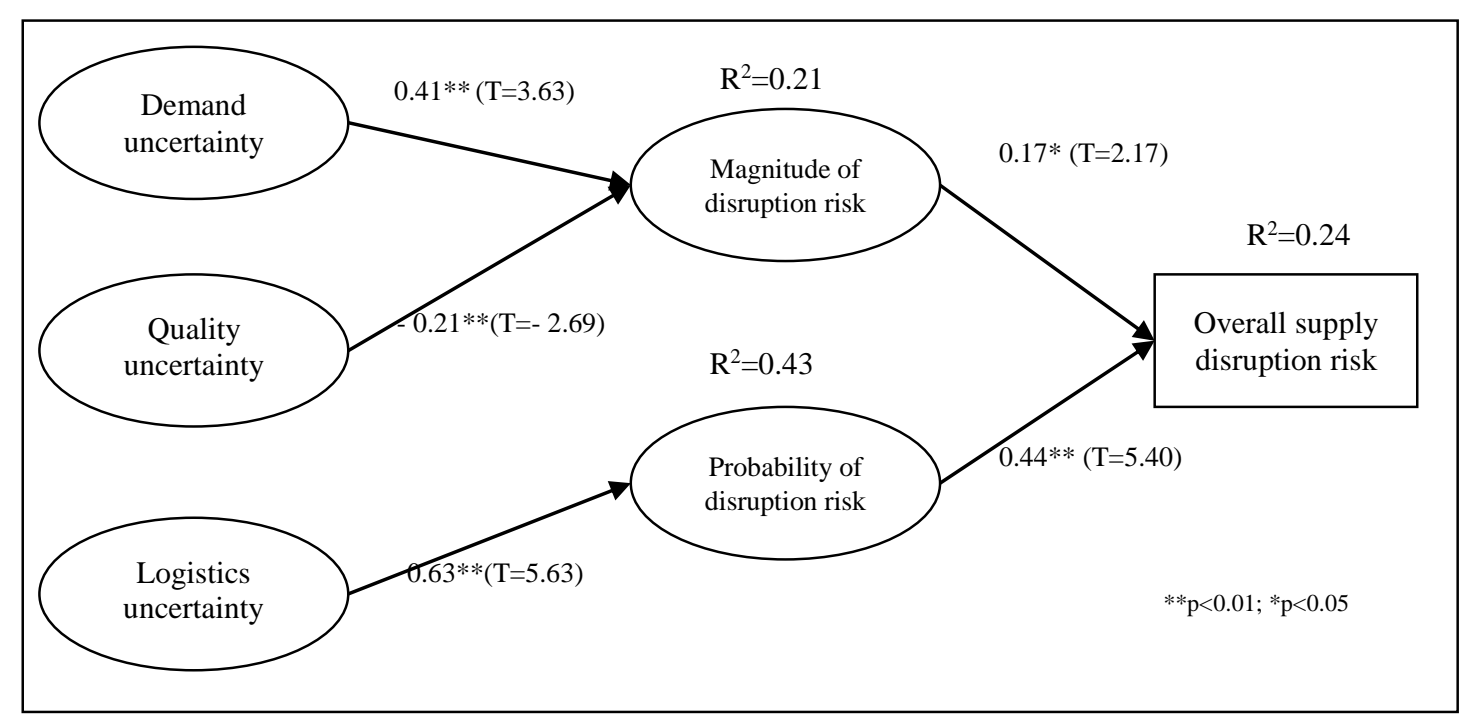

Figure 2. Structural model of supply disruption risk

As shown in Figure 2, five out of the eight structural links are significant. The results of the SEM analysis provide support for hypotheses H1, H6, H7 and H8. The relationship between quality uncertainty and magnitude of disruption risk (H3) is also significant, however the direction of the correlation is negative. The structural link between demand uncertainty and magnitude of risk is positive and significant (structure link=0.41, t-value $=3.63$, pvalue $<0.001)$. This finding suggests that demand uncertainty affects the perceived impact of supply chain disruption. 
The antecedents of disruption risk magnitude explain $21 \%$ of the variance in the magnitude of disruption risk. In addition, the structural link of logistics uncertainty and probability of risk is positive and significant (structure link=0.63, t-value=5.63, p-value $<0.001$ ), and explains $43 \%$ of the variance in the probability of disruption risk.

Our results indicate that both links associated with overall risk are positive and significant. The structural link between magnitude of risk and overall risk is $0.17, \mathrm{t}$-value $=2.176$ (pvalue $<0.001$ ), and the structural link between probability of risk and overall risk is 0.44 , $\mathrm{t}$ value $=5.205$ ( $\mathrm{p}$-value $<0.001)$. The magnitude and probability of risk explain $24 \%$ of the variance in the perceived overall risk.

\section{Discussion}

Our research contributes to supply chain disruption risk literature. More specifically, our research provides insight regarding the structure of supply chain disruption risk, in particular the Thai beverage context. Most of the literature in supply chain risk management focuses upon practices, with this research instead focusing on the understanding of risk perception of purchasing manager. The results provide support for the risk representation approach initially proposed by Ellis et al. (2010). Our findings also provide evidence that their basic structure of disruption risk model is suitable for representing disruption risk in beverage industrial context within other national contexts. In Ellis et al.'s (2010) work, the findings indicate that both magnitude and probability of disruption are determinants of upstream disruption risk in which probability of disruption has a more significant relationship with overall risk than risk magnitude. Our research returns similar findings, representing cumulative investigations within the domain of downstream disruption risk. The probability and the magnitude of risk are both significant, with the probability of loss having a more significant relationship. The result implies that in forming their perception of supply disruption risk, Thai beverage 
company managers give more emphasis to the probability of risk occurrence. This can be explained by the major role within beverage supply chains of beverage distributors, whose main target is to ensure the smoothness of the product flow from the manufacturer to its customers (Gebennini et al. 2013), rather than accounting for the compensation of loss to the customer when supply chain interruptions occur.

As a result, beverage firms need to establish more systematic procedures to assist the managers in transforming environmental uncertainty factors into performance measures, such as forecasting accuracy, logistics dependability, to assist in more accurate risk appraisal. Different uncertainty factors may only affect a particular risk dimensions but not all of them. Due to the proposed measurement items developed in this research having been through a robust scale development process, they could be used as an "uncertainty element checklist" to allow managers to assess the uncertainty factors in their firm's supply chain. Based on the findings of our research, firms can develop more effective risk management tool, particularly, more concise evaluation procedures before generating risk map/matrix and corresponding risk management action plans ( Norrman and Jannson, 2004 ).

Demand uncertainty is viewed as a major factor affecting the product flow of downstream supply chains (Chen et al. 2000). The beverage industry is particularly susceptible to demand uncertainty from retailers due to the presence of illegal, "grey market" products introducing additional variation to customer demand forecasting. Moreover, this uncertainty affects the magnitude of supply disruption risk. Our findings provide addition support for Germain et al. (2008) that demand uncertainties have a negative impact on firms' product offerings. When demand disruption occurs, the existing forecasting plan becomes inaccurate and the focal company may be unable to respond to demand changes. As a result of failing to respond to customer requirements, the company may suffer lost sales leading to reductions in financial 
performance as a result of being left with surplus stock. However, due to the construct reliability of demand uncertainty, the support given to $\mathrm{H} 1$ can only be considered as tentative.

The findings do not support the presence of a significant relationship between demand uncertainty and the probability of risk. This can be explained by the beverage company holding a certain level of safety stock of their major products. As a result, the company can still supply the products, even though a demand uncertainty often exists and it is very difficult for managers to predict customer demand. However, due to product expiry dates and SKU proliferation, it is not possible to hold high levels of safety stock to account for long term supply disruption. Some beverage products, such as dairy drink and fresh juice, also only have short expiry dates, combined with SKU proliferation, which lead to higher inventory costs (Schmitt and Singh 2012).

Given the large number of additional factors that can affect demand uncertainty, further research is required to more effectively conceptualize demand uncertainty within the context of supply disruption risk within this context.

Existing literature states that quality uncertainty is always viewed as an uncontrollable factor related to the supply of material (Tse and Tan 2011). However, in the context of the beverage industry, this argument is not supported and results are contrary to the extant research. The analysis shows that quality uncertainty is negatively related to the magnitude of supply disruption risk. This result provides a very interesting perspective in studying supply disruption risk. It implies that quality uncertainty reduces the magnitude of disruption risk in the beverage industry, rather than increasing the magnitude of supply chain disruption. This can potentially be explained via quality uncertainty, where a distributor may implement internal practices to mitigate against quality uncertainty and its negative impact of firm reputation, such as product inspection and developing alternate suppliers. This could be 
realized through the adoption of a multi-sourcing strategy, which $87 \%$ of respondents engaged in. Thus, companies appear to be prepared with contingencies to change suppliers when problems occur, allowing us to infer that quality uncertainty may affect risk management behaviour in order to reduce its impact. Alternatively, while pursuing multi-sourcing strategies may help maintain the supply of products, risks associated with product quality that may result in products that are unsafe to drink have a qualitatively different nature. With low switching costs for customers, quality uncertainty of product can have short and potentially long-term impact on customer demand. A potential outcome of this is the Thai Beverage industry reducing inventory levels to support rapid supply partner changes, requiring them to adopt an agile orientation. A final potential explanation is related to product recall resulting from safety issues. If customers perceive quality scandals from news sources or business partners, they prefer to cancel the order to avoid massive product withdrawal related to mislabelling or fraud (e.g. counterfeit spirits). Therefore, safety issues in the beverage industry reduce the impact of loss as a result of the customers voluntarily cancelling orders.

Logistics uncertainty is then identified as the major determinant of the probability of supply disruption risk. Variability in the logistics service directly influences the dependability of delivery service and increases the chance of supply disruption risk. In addition, the chance of environmental disturbance can also impact supply distribution risk. For example, the transportation network in Thailand was severely affected by flooding (Haraguchin and Lall 2014). However, while logistics uncertainty is found to impact the probability of disruption risk, there is no direct relationship with the magnitude of supply disruption risk. This may be due to two reasons: First, environmental incidents may cause considerable damage to the transportation network of the whole country, meaning that every company suffers a downstream supply chain disruption. The logistics uncertainty related to a natural disaster 
does not affect the firm to a great extent, as their competitors face the same problems. Secondly, the delay in product flow does not mean shortage of supply. Logistics uncertainty causes only a temporary interruption of product flow, which may happen frequently, meaning those supply chains suffering frequent shortages will develop short-term resilience (through safety stocks of key products). Alternatively, due to the awareness of the risk of natural disasters within Thailand, mitigating action (such as back up logistics providers or engaging with logistics providers who as less affected by a natural disaster) may be taken by practitioners to reduce the impact of logistics uncertainty. In addition, most beverage firms hold a level of safety stock or possess internal organizational competences that can cope with slight delays in receiving items resulting from logistics. Thus, there is no great impact on the company's performance and revenue.

\section{Conclusion}

While this study extends previous empirical investigations of the representation of supply disruption risk, several extensions can be made to this research area to add further insight. As this research has focused on the Thai beverage industry, it is important to test the generalizability of the findings to other countries and across other industries. Kristal et al. (2011) demonstrate that the effectiveness of different supply chain practices is affected by national culture, with Behara et al. (2014) demonstrating the lack of supply chain research in developing economies. Future research conducted using multi-group data sets could allow exploration of the effect of national context or the impact of operational context on disruption risk management practices. Larger groups would also assist in the examination of the moderating effect of firm size, industries and supply chain position on disruption risk perception. 
An important limitation of the study is that in collecting the data, only a single key respondent in each company was used. The use of a single respondents to rate diverse supply chain-related question items may generate some inaccuracy and increase random error (Cao and Zhang 2011). Future research should seek to utilize multiple respondents in each participating firm in order to improve the accuracy and to reduce the random error. Ketokivi and Schroeder (2004) note that multiple respondents provide perceptual measures that more effectively map objective data. Moreover, with the current research related to managerial perception, multiple respondents would also assist in determining how perceptions vary within a single organization.

Drawing from the results of this study, which are broadly consistent with Ellis et al. (2010), probability has a greater impact on disruption risk than magnitude. This may imply that managers hold an implicit model of risk management in which greater weight is given to frequently occurring issues, rather than magnitude and probability contributing to risk management equally. This may be due to distributor managers giving greater emphasis to smoothness of product flow, alternatively, it might also be caused by managers forgetting, consciously overlooking infrequently occurring events (natural disasters) or insuring against events that are outside managers' control. The result thus provides evidence and motivation for supply chain managers and directors to reflect on their implicit models of disruption risk, to ensure those areas they focus attention contribute to the management of both magnitude and probability of supply chain risk.

To further explore this alternative explanation, in addition to multiple response surveys, interviews with practitioners about particular "major" incidents may provide valuable, context rich data with which to explore this result. This process may help identify new disruption risk antecedents, build new constructs or even build new disruption risk theories. Alternatively, 
objective data, potentially from insurance companies, may provide alternative measures of supply chain risk to allow comparisons with perceptual measures.

The most interesting finding from the current research was the negative relationship between quality uncertainty and the magnitude of disruption risk. A broader explanation of this finding could be a nuance of the Thai beverage industry, due to the risks of counterfeit products and large impact of product quality concerns. Further research into this result would shed light on how a developing national and fast moving product context behave to prevent quality risk affecting firm performance. With other national and product contexts exhibiting similar characteristics, such insight holds potential to shed light both within the domain of supply disruption risk, but also agile supply management practices.

In summary, this study has focused exclusively on conceptualizing the supply chain uncertainty factors of downstream disruption risk, and their impact on risk constitution. Based on the synthesis of research findings and the new insights from this research, practitioners can refer to this study to plan their sourcing, logistics and quality strategies. Moreover, researchers can scrutinize how additional factors may affect disruption risk by applying current constructs within different operational contexts. In short, the proposed disruption model provides a basis for academics and managers to understand downstream disruption risk, and provides direction for managers to identify potential environmental uncertainties in their supply chains. Taken together, the contributions of the current research are consistent with many of the research directions presented by Colicchia and Strozzi (2012). This reiterates the timely and relevant nature of the current study to the continued development of research within the domain of supply chain risk management. 


\section{References}

Armstrong, Paul. 2011. "Thai floods reduce beer supplies to a drip." CNN, Business 360, access on 01/09/2013 <http://business.blogs.cnn.com/2011/11/08/thai-floods-reducebeer-supplies-to-a-drip/\%3E.

Behara, Ravi S., Sunil Babbar, and Philip Andrew Smart. 2014. "Leadership in OM research: a social network analysis of European researchers." International Journal of Operations \& Production Management 34 (12):1537-1563.

Braunscheidel, Micheal J., and Nallan C. Suresh. 2009. "The organizational antecedents of a firm's supply chain agility for risk mitigation and response." Journal of Operations Management 27 (2):119-140.

Brislin, R. W. . 1980. "Translation and context analysis of oral and written material." In Handbook of Cross-Cultural Psychology: Methodology., edited by H. C. Triandis and J. W. Berry, 389-444. Boston: Allyn \& Bacon.

Cao, Mei, and Qingyu Zhang. 2011. "Supply chain collaboration: Imapct on collaborative advantage and firm performance." Journal of Operations Management 29 (3):163180.

Chen, F., Z. Drezner, J. Ryan, and D. Simchi-Levi. 2000. "Quantifying the bullwhip effect in a simple supply chain: The impact of forecasting, lead times and information." Management Science 46 (3):436- 443.

Chopra, S.C., and M.S. Sodhi. 2004. "Managing risk to avoid supply chain breakdown." $M I T$ Sloan Management Review 46:53-61.

Churchill, G. A. 1979. "A paradigm for developing better measures of marketing constructs." Journal of Marketing Research 16 (1):64-72.

Colicchia, Claudia, and Fernanda Strozzi. 2012. "Supply chain risk management: a new methodology for a systematic literature review." Supply Chain Management: An International Journal 17 (4):403-418.

Craighead, Christopher W., Jennifer Blackhurst, M. Johnny Rungtusanatham, and Robert B. Handfield. 2007. "The Severity of Supply Chain Disruptions: Design Characteristics and Mitigation Capabilities." Decision Sciences 38 (1):131-156.

Cunningham, S.M. . 1967. The Major Determinants of Perceived Risk. Boston.: Harvard University.

DeVellis, R. F. . 2003. "Scale development: theory and applications." In Applied Social Research Methods. Newbury Park. California: Sage Publication.

Dillman, Don A. 1978. Mail and Telephone urveys: The Tota Design Method. New York: Wiley-Interscience.

Dowling, G.R. 1986. "Perceived Risk: The Concept and Its Measurement." Psychology and Marketing 3:193-211.

Ellis, Scott C., Raymond M. Henry, and Jeff Shockley. 2010. "Buyer perceptions of supply disruption risk: A behavioral view and empirical assessment." Journal of Operations Management 28 (1):34-46.

Feng T, Keller L, Wang L, Wang Y. 2010. "Product Quality Risk Perceptions and Decisions: Contaminated Pet Food and Lead-Painted Toys." Risk Analysis 30 (10):1572-1589

Fornell, C., and D.F. Larcker. 1981. "Structural equation models with unobservable variables and measurement error: algebra and statistics." Journal of Marketing Research 18 (3):382-388.

Gebennini, Elisa, Andrea Grassi, Bianca Rimini, and Eleonora Depietri. 2013. "Costs and opportunities of moving picking activities upstream in distribution networks: A 
case study from the beverage industry." International Journal of Production Economics 143 (2):342-348.

Germain, Richard, Cindy Claycomb, and Cornelia Dröge. 2008. "Supply chain variability, organizational structure, and performance: The moderating effect of demand unpredictability " Journal of Operations Management 26 (5):557-570.

Giunipero, Larry C., and Reham Aly Eltantawy. 2004. "Securing the upstream supply chain: a risk management approach." International Journal of Physical Distribution \& Logistics Management 34 (9):698-713.

Gülpınar, Nalan, Ethem Canakoglu, and Dessislava Pachamanova. 2014. "Robust investment decisions under supply disruption in petroleum markets." Computers \& Operations Research 44:75-91.

Haraguchin, Masahiko, and Upmanu Lall. 2014. "Flood risks and impacts: A case study of Thailand's floods in 2011 and research questions for supply chain decision making." International Journal of Disaster Risk Reduction doi:10.1016/j.ijdrr.2014.09.005.

Hendricks, Kevin B., and Vinod R. Singhal. 2005. "An Empirical Analysis of the Effect of Supply chain Disruptions on Long-Run Stock Price Performance and Equity Risk of the Firm." Production and Operations Management 14 (1):35-52.

Hinkin, T. R. 1995. "A review of scale development practices in the study of organizations." Journal of Management 21 (5):967-988.

Jüttner, Uta, Helen Peck, and Martin Christopher. 2003. "Supply Chain Risk Management: Outlining an Agenda for Future Research." International Journal of Logistics: Research and Applications 6 (4):197-210.

Kaynak, H., and J. L. Hartley. 2006. "Using replication research for just-in-time purchasing construct development." Journal of Operations Management

24 (6):868-892.

Ketokivi, Mikko A., and Roger G. Schroeder. 2004. "Perceptual measures of performance: fact or fiction?" Journal of Operations Management 22 (3):247-264. doi: DOI: 10.1016/j.jom.2002.07.001.

Kleindorfer, Paul R., and Germaiine H. Saad. 2005. "Managing Disruption Risks in Supply Chains." Production and Operations Management 14 (1):53-68.

Kristal, Mehmet, Mark Pagell, Chenlung Yang, and Chwen Sheu. 2011. "Are supply chain management theories culturally constrained? An empirical assessment." Operations Management Research 4 (1):61-73. doi: 10.1007/s12063-011-0048-4.

Lee, H.L. . 2002. "Aligning Supply Chain Strategies with Product Uncertainties." California Management Review 44:105-119.

Lockamy III, Archie. 2014. "Assessing disaster risks in supply chains." Industrial Management \& Data Systems 114 (5):755-777.

McDaniels T, Axelrod L, Slovic P. 1995. "Characterizing perception of ecological risk" Risk Analysis 15(5):575-588.

Menor, Larry J., and Aleda V. Roth. 2007. "New service development competence in retail banking: Construct development and measurement validation " Journal of Operations Management 25 (4):825-846.

Mitchell, V.W. 1995. "Organisational risk perception and reduction: a literature review." British Journal of Management 6 (2):115-133.

Netemeyer, R. G., W. O. Bearden, and S Sharma. 2003. Scaling procedures: Sage Publication, Inc. 
Norrman, A. , and U. Jansson. 2004. "Ericsson's proactive supply chain risk management approach after a serious sub-supplier accident." International Journal of Physical Distribution \& Logistics Management 34 (5):434-456.

Nunnally, J. C. 1978. Psychometric theory: MeGraw-hill. Inc.

NZTE. 2011. "New Zealand Trade and Enterprise - Exporter guide: Thailand food and Beverage, [online] Available at: http://www.nzte.govt.nz/explore-exportmarkets/market-research-by-industry/Food-81 andbeverage/Documents/Thailand\%20Food\%20and\%20Beverage\%20Market\%20Prof ile\%20 \%20June\%202011.pdf [Accessed 5 September 2011]."

Peter, J.P., and M.J. Ryan. 1976. "An investigation of perceived risk at the brand level." Journal of Marketing Research 13 (2):184-188.

Rao, Shashank, and Thomas J. Goldsby. 2009. "Supply chain risks: a review of typology." The international Journal of Logistics Management 20 (1):97-123.

Revilla, E., and M. J. Sáenz. 2014. "Supply chain disruption management: Global convergence vs national specificity. ." Journal of Business Research 67 (6):11231135 .

Rice, James B., and Federico Caniato. 2003. "Building a secure and resilient supply network." Supply chain management review 7 (5):22-30.

Savadori L, Savio S, Nicotra E, Rumiati R, Finucane M, Slovic P. 2004. "Expert and Public Perception of Risk from Biotechnology" Risk Analysis. 24(5):1289-1299.

Schmitt, A. J., and M. Singh. 2012. "A quantitative analysis of disruption risk in a multiechelon supply chain." International Journal of Production Economics 139 (1):22-32.

Schwab, D. P., ed. 1980. Construct validity in organization behavior. Edited by B. M. Staw and L. L. Cummings. Vol. 2, Research in organizational behavior. Greenwich: JAI press.

Shah, Rachna, and Susan Meyer Goldstein. 2006. "Use of Structural equation modeling in operations management research: Looking back and forward." Journal of Operations Management 24 (2):148-169.

Silbermayr, Lena, and Stefan Minner. 2013. "A multiple sourcing inventory model under disruption risk." International Journal of Production Economics.

Sjöberg, L., B.E. Moen, and T. Rundmo. 2004. Explaining risk perception. An evaluation of the psychometric paradigm. Trondheim: Rotunde publications 84 .

Slovic, P., MacGregor, D., \& Kraus, N. N. (1987). Perception of risk from automobile safety defects. Accident Analysis \& Prevention, 19(5), 359-373.

Srinivasan, Mahesh, Debmalya Mukherjee, and Ajai S. Gaur. 2011. "Buyer-supplier partnership quality and supply chain performance: Moderating role of risks, and environmental uncertainty." European Management Journal 29:260-270.

Tang, Ou, and S. Nurmaya Musa. 2011. "Identifying risk issues and research advancements in supply chain risk management." International Journal of Production Economics 133 (1):25-34.

Terry, Lisa. 2008. "Snapshot: Beverage Companies Thirst for Supply Chain Efficiency." Inbound Logistics Magazine.

Thun, Jorn-Henrik, and Daniel Hoenig. 2011. "An empirical analysis of supply chain risk management in the German automotive industry." International Journal of Production Economics 131:242-249.

Tomlin, Brian. 2006. "On the Value of Mitigation and Contingency Strategies for Managing Supply Chain Disruption Risks." Management Science 52 (5):pp. 639-657. 
Tomlin, Brian, and Yimin Wang. 2011. "Operational Strategies for Managing Supply Chain Disruption Risk." In Handbook of Integrated Risk Management in Global Supply Chains, edited by Panos Kouvelis, Lingxiu Dong, Onur Boyabatli and Rong Li. JohnWiley\&Sons, Inc.

Tse, Y. K., and K. H. Tan. 2012. "Managing product quality risk and visibility in multi-layer supply chain." International Journal of Production Economics 139 (1):46-57.

Tse, Ying Kei, and Kim Hua Tan. 2011. "Managing product quality risk in a multi-tier global supply chain " International Journal of Production Research 49 (1):139-158.

Tyler, David, Jo Heeley, and Tracy Bhamra. 2006. "Supply chain influences on new product development in fashion clothing " Journal of Fashion Marketing and Management 10 (3):316-328.

Waters, Donald. 2007. Supply Chain Risk Management: Vulnerability and Resilience in Logistics: Kogan Page Limited, UK.

Wilson, M.C. . 2007. "The impact of transportation disruption on supply chain performance." Transportation Research Part E: Logistics and Transportation Review 43 (4):295320.

Worthington, R. L., and T. A. Whittaker. 2006. "Scale Development Research: A content analysis and recommendations for best practices." The Counseling Psychologist 34:806-838.

Wu, T., J. Blackhurst, and P. O'grady. 2007. "Methodology for supply chain disruption analysis." International Journal of Production Research 45 (7):1665-1682.

Yang, Zhibin (Ben), Göker Aydýn, Volodymyr Babich, and Damian R. Beil. 2009. "Supply Disruptions, Asymmetric Information, and a Backup Production Option." Management Science 55 (2):192-209.

Yates, J.F., and E.R. Stone. 1992. Risk appraisal. Edited by J.F. Yates, Risk-taking Behavior. New York: John Wiley \& Sons.

Appendix 1 - Measurement items

\# Item dropped in exploratory factor analysis

\begin{tabular}{|l|l|}
\hline Demand uncertainty & Reference \\
\hline $\begin{array}{l}\text { DU1 Rumours of price increases affect the level of safety stock we hold. } \\
\text { \# }\end{array}$ & Chen et al. (2000) \\
\hline DU2 Customer orders do not follow a monthly ordering pattern. & Lee et al. (2000) \\
\hline DU3 We do not know our customers' stock levels of our product. \# & Chen et al. (2000) \\
\hline $\begin{array}{l}\text { DU4 Compared to our competitors, our demand forecasting is } \\
\text { inaccurate. }\end{array}$ & Chen et al. (2000) \\
\hline $\begin{array}{l}\text { DU5 The accuracy of our demand forecasting is affected by illegal 'grey } \\
\text { market' product. }\end{array}$ & Tyler et al. (2006) \\
\hline
\end{tabular}




\begin{tabular}{|l|l|}
\hline Quality uncertainty & Reference \\
\hline $\begin{array}{l}\text { QU1 Suppliers often supply poor quality products (expired or physically } \\
\text { damaged). }\end{array}$ & $\begin{array}{l}\text { Ravi (2006) and } \\
\text { Tse and Tan } \\
(2012)\end{array}$ \\
\hline QU2 Product recalls/withdrawals often occur due to poor quality. & $\begin{array}{l}\text { Tse and Tan } \\
(2012)\end{array}$ \\
\hline $\begin{array}{l}\text { QU3 There is often large variation in product quality received from our } \\
\text { suppliers }\end{array}$ & $\begin{array}{l}\text { Tse and Tan } \\
\text { (2012) }\end{array}$ \\
\hline $\begin{array}{l}\text { QU4 Large batches of products are often returned to suppliers due to } \\
\text { quality problems. }\end{array}$ & $\begin{array}{l}\text { Tse and Tan } \\
(2012)\end{array}$ \\
\hline
\end{tabular}

\begin{tabular}{|l|l|}
\hline Logistics uncertainty & Reference \\
\hline LU1 The dependability of our logistics service is low. & $\begin{array}{l}\text { Chopra and Sodhi } \\
(2004)\end{array}$ \\
\hline LU2 Our logistics provider is unable to provide a reliable service. & $\begin{array}{l}\text { Chopra and Sodhi } \\
(2004), \\
\text { Wilson (2007) }\end{array}$ \\
\hline $\begin{array}{l}\text { LU3 Deliveries are always behind schedule due to poor fleet } \\
\text { management by the logistics provider. }\end{array}$ & Wilson (2007) \\
\hline $\begin{array}{l}\text { LU4 Natural disaster (e.g. flood) always causes instability in logistics } \\
\text { service. }\end{array}$ & Newly developed \\
\hline
\end{tabular}

\begin{tabular}{|l|l|}
\hline Overall supply disruption risk & \\
\hline $\begin{array}{l}\text { OR1 Overall, disruption in the downstream supply chain is } \\
\text { characterized by high levels of risk. }\end{array}$ & Ellis et al. (2010) \\
\hline
\end{tabular}

\begin{tabular}{|l|l|}
\hline Magnitude of supply chain disruption & \\
\hline $\begin{array}{l}\text { MD1 An interruption in the supply of product to customers would have } \\
\text { severe negative consequence for our business. }\end{array}$ & Ellis et al. (2010) \\
\hline $\begin{array}{l}\text { MD2 Poor delivery performance would affect our relationship with } \\
\text { customers. }\end{array}$ & Ellis et al. (2010) \\
\hline $\begin{array}{l}\text { MD3 We would incur significant costs and/or losses in revenue if we } \\
\text { failed to supply the customer's demand. }\end{array}$ & Ellis et al. (2010) \\
\hline
\end{tabular}

\begin{tabular}{|l|l|}
\hline Probability of supply chain disruption & \\
\hline $\begin{array}{l}\text { RP1 There is a high probability that our supply of product to customers } \\
\text { will have a disruption. }\end{array}$ & Ellis et al. (2010) \\
\hline $\begin{array}{l}\text { RP2 There is a high probability that we could not supply product to the } \\
\text { customers on time. }\end{array}$ & Ellis et al. (2010) \\
\hline $\begin{array}{l}\text { RP3 There are often unforeseen circumstances that will affect our } \\
\text { ability to supply product to customers. }\end{array}$ & Ellis et al. (2010) \\
\hline
\end{tabular}




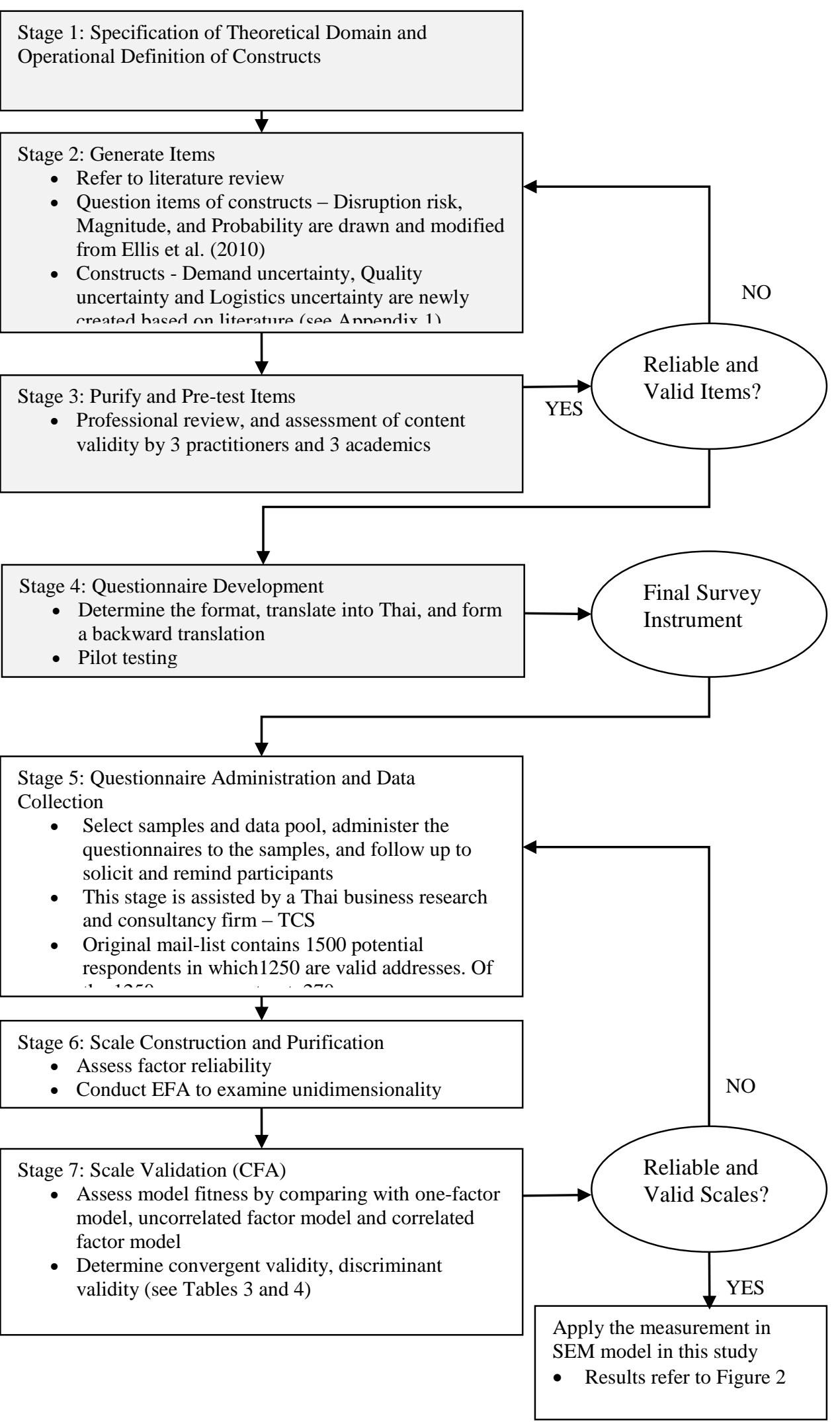

